\title{
Importância da nova lei para higienização de carrinhos de supermercados: questões
}

\section{diretas e indiretas}

\author{
Importance of the new law for hygienization of supermarket trolleys: direct and indirect issues \\ Importancia de la nueva ley de saneamiento de carrito de supermercados: problemas directos e \\ indirectos
}

Recebido: 04/08/2021 | Revisado: 10/08/2021 | Aceito: 13/08/2021 | Publicado: 15/08/2021

Lorena Queiroz Rachid

ORCID: https://orcid.org/0000-0002-6728-5261

Universidade Federal da Bahia, Brasil

E-mail: lore_rachid@hotmail.com

Sandra Rojas Duailibi

ORCID: https://orcid.org/0000-0001-7373-0950 Estácio de Sá, Brasil

E-mail: srdconsultoria@gmail.com

Bruna Silva Araújo

ORCID: https://orcid.org/0000-0003-4140-8224

Universidade Salvador, Brasil

E-mail: bruna_bsaraujo@hotmail.com

\begin{abstract}
Resumo
O objetivo deste estudo é discutir a importância da segurança do alimento e a proteção do consumidor na utilização dos carrinhos de supermercado. Trata-se de uma revisão de literatura na busca de artigos realizada na Biblioteca Virtual (Scielo) e CAPES, utilizando descritores referentes à micro-organismos, contaminação cruzada, Boas Práticas de Fabricação, higienização de carrinhos em supermercados, segurança do alimento e fiscalização sanitária. Ainda, foram consultadas as referências dos artigos selecionados, a fim de identificar outros estudos. O presente estudo caracterizase quanto ao objetivo em uma pesquisa explicativa que tenha como propósito identificar fatores que determinam ou contribuam para a ocorrência de fenômenos. Quanto ao delineamento, a pesquisa configura um estudo bibliográfico, esta se caracteriza pelo estudo de materiais já elaborados. A pesquisa bibliográfica também é utilizada para catalogar as produções científicas. Quanto à natureza, o estudo se classifica como qualitativo, pois é procedida uma análise sobre o conteúdo escrito dos artigos, para se averiguar as principais metodologias adotadas nos estudos investigados. A técnica de coleta é uma documentação indireta com documento e bibliografia, juntamente com técnicas de análise de dados qualitativas. Os dados encontrados contribuíram para resultados sobre avaliações realizadas no meio alimentício e os diversos patógenos encontrados nos diversos ambientes. O que remete as questões diretas e indiretas sobre contaminações advindas de higiene pessoal, ambiente de trabalho, animais no local, microrganismo de feira livres, condições higiêncio-sanitário, ou seja, esses requesitos mencionados contribuem para a proliferação de contaminantes. Sendo de muita importância a prevenção através da higienização e sanitização de ambientes, equipamentos e mãos. Conclui-se que é necessário o acompanhamento em longo prazo e de treinamentos em Boas Práticas de Fabricação nos estabelecimentos alimentícios para melhor alcance da padronização e controle da qualidade.
\end{abstract}

Palavras-chave: Micro-organismos; Contaminação cruzada; Boas práticas de fabricação; Higienização de carrinhos em supermercados; Segurança do alimento; Fiscalização sanitária.

\footnotetext{
Abstract

The aim of this study is to discuss the importance of food safety and consumer protection when using supermarket carts. This is a literature review in the search for articles carried out in the Virtual Library (Scielo) and CAPES, using descriptors referring to microorganisms, cross contamination, Good Manufacturing Practices, hygiene of supermarket carts, food safety and sanitary inspection. Also, the references of selected articles were consulted in order to identify other studies. The present study is characterized as the objective in an explanatory research that aims to identify factors that determine or contribute to the occurrence of phenomena. As for the design, the research configures a bibliographic study, which is characterized by the study of materials already prepared. Bibliographic research is also used to catalog scientific productions. As for the nature, the study is classified as qualitative, as an analysis is carried out on the written content of the articles, in order to ascertain the main methodologies adopted in the investigated studies. The collection technique is an indirect documentation with document and bibliography, together with qualitative data analysis techniques. The data found contributed to results on evaluations carried out in the food environment and the various pathogens found in different environments. Which refers to direct and indirect questions about contaminations arising from personal hygiene, work environment, animals on site, free market microorganism, hygienic-sanitary conditions,
} 
that is, these mentioned requirements contribute to the proliferation of contaminants. Prevention is very important through cleaning and sanitizing environments, equipment and hands. It is concluded that long-term monitoring and training in Good Manufacturing Practices in food establishments is necessary to better achieve standardization and quality control.

Keywords: Microorganisms; Cross contamination; Good manufacturing practices; Cleaning of trolleys in supermarkets; Food safety; Health inspection.

\begin{abstract}
Resumen
El objetivo de este estudio es discutir la importancia de la seguridad alimentaria y la protección del consumidor en el uso de carritos de supermercado. Se trata de una revisión de la literatura en la búsqueda de artículos realizada en la Biblioteca Virtual (Scielo) y CAPES, utilizando descriptores referentes a microorganismos, contaminación cruzada, Buenas Prácticas de Manufactura, higiene de carritos de supermercado, seguridad alimentaria e inspección sanitaria. Asimismo, se consultaron las referencias de los artículos seleccionados para identificar otros estudios. El presente estudio se caracteriza por ser el objetivo de una investigación explicativa que tiene como objetivo identificar los factores que determinan o contribuyen a la ocurrencia de fenómenos. En cuanto al diseño, la investigación configura un estudio bibliográfico, que se caracteriza por el estudio de materiales ya elaborados. La investigación bibliográfica también se utiliza para catalogar las producciones científicas. En cuanto a la naturaleza, el estudio se clasifica como cualitativo, ya que se realiza un análisis del contenido escrito de los artículos, con el fin de conocer las principales metodologías adoptadas en los estudios investigados. La técnica de recolección es una documentación indirecta con documento y bibliografía, junto con técnicas de análisis de datos cualitativos. Los datos encontrados contribuyeron a los resultados de las evaluaciones realizadas en el entorno alimentario y los diversos patógenos encontrados en diferentes entornos. Lo cual se refiere a preguntas directas e indirectas sobre contaminaciones derivadas de la higiene personal, ambiente de trabajo, animales en sitio, microorganismos de libre mercado, condiciones higiénico-sanitarias, es decir, estos requisitos mencionados contribuyen a la proliferación de contaminantes. La prevención es muy importante mediante la limpieza y desinfección de entornos, equipos y manos. Se concluye que el monitoreo y la capacitación a largo plazo en Buenas Prácticas de Manufactura en los establecimientos de alimentos es necesario para lograr una mejor estandarización y control de calidad.
\end{abstract}

Palabras clave: Microorganismos; Contaminación cruzada; Buenas prácticas de fabricación; Limpieza de carros en supermercados; Seguridad alimenticia; Inspección sanitaria.

\title{
1. Introdução
}

A demanda dos atributos de qualidade remete-se as consequências danosas que o consumidor vem sendo exposto, sem contar com prejuízos econômicos dos estabelecimentos pela perda de cliente para a concorrência. A inocuidade de alimentos ficou em evidência em função de muitos casos envolvendo alimentos e riscos à saúde no decorrer dos últimos anos (Rios, 2012).

As redes de supermercados por também possuírem grande gama de contaminantes, assim como as feiras livres, obtiveram bastante relevância para a efetivação da Lei com abrangência Federal. Segundo Silva eCorreia (2009), supermercados e feiras livres obtiveram índices variáveis de contaminantes, sendo similares entre as amostras das duas localidades.

No geral, o comércio varejista no Brasil destaca-se pelo otimismo, expectativas e dinamismo no mercado consumidor, que advém muitas oportunidades ao setor em questão. A princípio apresenta-se como negócio simples, porém com muita intensidade detalhes que determinam ganhos e riscos (Serretino, 2012).

A partir desses riscos que vêm as preocupações, como por exemplo, a questão da higienização. Esta é fundamental em qualquer estabelecimento alimentício, inclusive supermercados.

É necessário a melhoria de alicerces higiênicos estabelecimentos e de fiscalização por parte dos órgãos competentes. A higienização é crucial para evitar contaminação e futuros problemas à saúde relacionados às doenças transmitidas por alimentos (DTA) (Pinho, 2020).

Aspectos biológicos, químicos ou físicos estão relacionados às DTAs e que ocasiona riscos à saúde provenientes de quando são expostos aos perigos de contaminação que gera danos à saúde. Pode envolver ingestão de alimentos ou contaminação cruzada que podem ou não estar contaminados como por exemplo: alimentos contaminados com substâncias tóxicas em seu organismo, microrganismos patogênicos, objetos lesivos e substâncias químicas (Sousa, 2020). 
Segundo Freitas (2018), inclusive a água utilizada tanto no processamento de alimentos como na higienização de superfícies, utensílios e equipamentos pode ser considerada veículo para disseminação de doenças. Etapas de higienização mal direcionadas podem gerar consequências referentes à segurança alimentar. Uma questão intolerável, é que mesmo que algo não esteja na vista do cliente deve estar limpo, pois do contrário refletirá na qualidade do produto (Rios, 2012). Devido a isso, devese manter essa higienização conciliada às boas práticas evitando aparecimentos de micro-organismos e/ou reflexos de contaminação cruzada; como ocorre em carrinhos de supermercados atualmente.

Segundo Macedo (2020), a água usada em diversos estabelecimentos comerciais de alimentos pode ser fonte de contaminação, sendo assim deve haver controle para atestar seu uso com segurança biológica. No caso de uma solução alternativa de abastecimento, a potabilidade deve ser atestada semestralmente, através de laudos laboratoriais.

Além disso há ainda os riscos à saúde humana pela contaminação cruzada de alimentos de origem animal. Que pode ser contaminado por transferência de micotoxinas, o que gera um fato relevante para a saúde da população (Assis, et al., 2019).

De acordo com Oliveira et al. (2015), é de extrema importância a prática de higienização dos carrinhos e cestas de supermercados, a fim de reduzir a contaminação dos indivíduos que fazem uso desses equipamentos, pois tais micro-organismos são agentes de infecções tanto superficiais como também invasivas em pessoas suscetíveis.

Segundo Silva e Correia (2009), as boas práticas de fabricação são fundamentais para o controle de qualidade, juntamente com treinamentos para colaboradores. As empresas alimentícias, por exemplo, tendem a aprimorar esta implantação, devido ao mercado consumidor e concorrências. Isso se dá principalmente para evitar a insegurança alimentar dos seus produtos, o que gera um diferencial na área da indústria.

A displicência com estas práticas efetivamente gera a falta de segurança alimentar em estabelecimentos alimentícios o que ocasiona na intervenção da legislação por intermédio da defesa do consumidor. Segundo Gruetzmann (2015), a imposição do Código de Defesa do Consumidor obriga o fornecedor a dar informação aos consumidores acerca de seus produtos e desta forma obter benefícios. Sendo assim, o principal objetivo do Legislador é de ter-se à disposição no mercado de consumo, produtos seguros que não tragam riscos à saúde.

Há também órgãos relacionados com a produção segura dos alimentos como: MAPA (Ministério de agricultura, Pecuária e Abastecimento), o MS (Ministério da Saúde) e a ANVISA (Agência Nacional de Vigilância Sanitária).

Diante disso, fazem-se necessários constantes aperfeiçoamentos no controle sanitário em todos os setores de uma rede de supermercados. As ferramentas legais, as próprias legislações, regulamentam os padrões higiênico-sanitários que devem ser seguidos pelo estabelecimento que lida com alimentos (Rios, 2012).

Atualmente a segurança dos alimentos visa a oferta de alimentos ausentes de agentes que causam risco ao consumidor. Com isso há o cumprimento das regulamentações instituídas pelas legislações e normas vigentes como a Resolução RDC 216 (BRASIL, 2004), que remete o Regulamento Técnico de Boas Práticas para Serviços de Alimentação, a Resolução RDC 275 (BRASIL, 2002), que regulamenta Técnico de Procedimentos Operacionais Padronizados aplicados aos Estabelecimentos Produtores/Industrializadores de Alimentos e o listamento de Verificação das Boas Práticas de Fabricação em Estabelecimentos Produtores/Industrializadores de Alimentos devem ser avaliados.

Com relação à Resolução - RDC 216 que aprova o regulamento técnico de Boas Práticas para Serviços de Alimentação em nível nacional pode ser complementada por órgãos de vigilância sanitária estadual, distritais e municipais que visam abranger requisitos inerentes à realidade local, sendo um apoio para estabelecer coerências diante das fiscalizações.

\section{Metodologia}

Neste artigo utilizou-se como metodologia a revisão bibliográfica que consiste na procura de referências teóricas para análise do problema de pesquisa. 
O presente estudo caracteriza-se quanto ao objetivo que uma pesquisa explicativa tenha como propósito identificar fatores que determinam ou contribuam para a ocorrência de fenômenos. Quanto ao delineamento, a pesquisa configura um estudo bibliográfico, estas se caracterizam pelo estudo de materiais já elaborados. A pesquisa bibliográfica também é utilizada para catalogar as produções científicas. Quanto à natureza, o estudo se classifica como qualitativo, pois é procedida uma análise sobre o conteúdo escrito dos artigos, para se averiguar as principais metodologias adotadas nos estudos investigados. A técnica de coleta é um documentação indireta com documentos e bibliografia, juntamente com técnicas de análise de dados qualitativas (Estrela, 2018).

As referências foram baseadas nas publicadas entre 2008 e 2018 contribuindo com a atualização no assunto abordado. A busca de artigos foi feita na Biblioteca Virtual em Saúde (Scielo) e portal da CAPES, utilizando descritores referentes à higienização, rede alimentícia e segurança de alimentos.

Sendo assim, foram apresentados e discutidos artigos achados na literatura baseados nas palavras-chave pesquisadas. A princípio os resultados de artigos apareceram em uma tabela com a seguinte exposição: Título, referência, ano e resultados. Na sequência os artigos foram correlacionados para discussão quanto a tipos de micro-organismos presentes, importância das Boas Práticas de Fabricação, higienização de carrinhos em supermercados e Fiscalização sanitária.

\section{Resultados e Discussão}

Tabela 1: Resultados de dados,

\begin{tabular}{|c|c|c|c|c|}
\hline DADOS & TÍTCL0 & REFERENNCIA & ANO & RESULTADOS \\
\hline 1 & $\begin{array}{l}\text { BRASIL. Decreto No } \\
13.486 \text {, de } 03 \text { de outubro } \\
\text { de } 2017 \text {. }\end{array}$ & $\begin{array}{l}\text { BRASIL. Decteto } \mathbb{N}^{\circ} \\
13.486 \text {, de } 03 \text { de outubto } \\
\text { de } 2017 \text {. }\end{array}$ & 2017 & 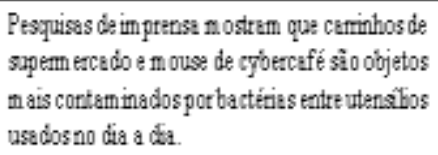 \\
\hline 2 & 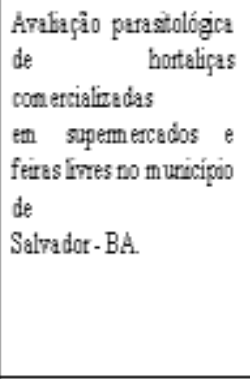 & SANTOS et al & 2009 & 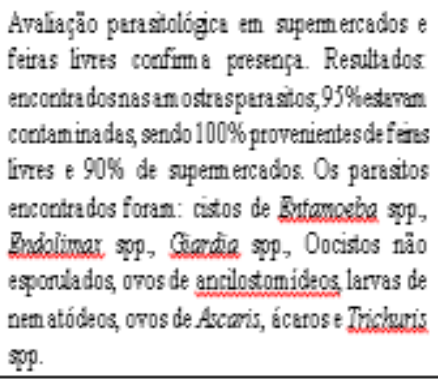 \\
\hline 3 & 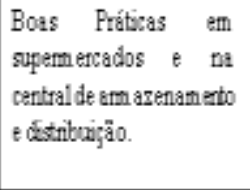 & RIOS, T.C. & 2012 & 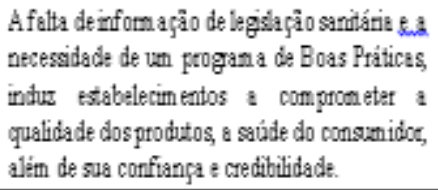 \\
\hline 4 & 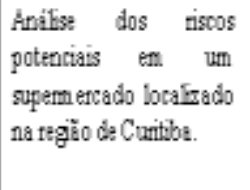 & SCHAMNE, A.N. & 2014 & 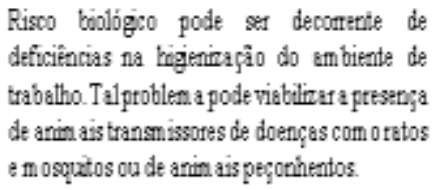 \\
\hline 5 & $\begin{array}{l}\text { Manual de Boes Práticas } \\
\text { de Fabricrção para } \\
\text { Incuistria fracionadora de } \\
\text { Alim entios. }\end{array}$ & $\begin{array}{l}\text { SLVVA, L. A ds; } \\
\text { CORRELA, A. F.K de. }\end{array}$ & 2009 & 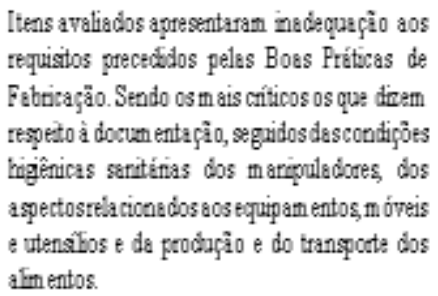 \\
\hline
\end{tabular}

Fonte: Autores (2019). 
Tabela 2: Resultados de dados.

\begin{tabular}{|c|c|c|c|c|}
\hline DADOS & TÍTUL0 & REFERÊNCIA & ANO & RESULTADOS \\
\hline 6 & $\begin{array}{l}\text { Caracterização de } \\
\text { Staphylococcus aureus } \\
\text { isolados da barra de mão } \\
\text { de carrinhos e alças de } \\
\text { cestas de } \\
\text { superm ercados }\end{array}$ & OLIVEIRA, D. B. de. et al. & 2015 & $\begin{array}{l}0 \text { estudo confirma } 0 \text { isolam ento de } \\
\text { Staphylococcus aureus. Demostraram que } 75 \\
\text { am ostras }(62,5 \%) \text { constatavam presença, sendo } \\
\text { que, desse total, } 35 \text { am ostras }(46,7 \%) \text { foram } \\
\text { isoladas de carrinhos e } 40(53,3 \%) \text { de cestas. É } \\
\text { de extrem a importância a higienização desses } \\
\text { objetos, a fim de diminuir os riscos de } \\
\text { contaminação na comunidade. }\end{array}$ \\
\hline 7 & $\begin{array}{l}\text { Direito de inform ação do } \\
\text { consumidor e rotulagetm } \\
\text { de alim entos. }\end{array}$ & GRUETZMANN, P.Q. & 2015 & $\begin{array}{l}\text { A imposição do Código de Defesa do } \\
\text { Consumidor é a principal intenção do } \\
\text { Legislador, para que se tenha à disposição no } \\
\text { mercado de consumo, produtos seguros, } \\
\text { confiáveis e que não apresentem riscos à saúde } \\
\text { de seus consumidores. }\end{array}$ \\
\hline 8 & $\begin{array}{l}\text { Perfil das denúncias } \\
\text { recebidas pelo Programa } \\
\text { de Alimentos da } \\
\text { Viglância Sanitária de } \\
\text { Viamão-RS. }\end{array}$ & PILLA, C. S. & 2009 & $\begin{array}{l}\text { A maioria das denúncias é sobre } \\
\text { superm ercados A razãopode ser por atenderem } \\
\text { um núm ero maior de clientes e também por } \\
\text { possuirem diversas áreas de manipulação } \\
\text { predispondo a mais riscos e mais denúncias. }\end{array}$ \\
\hline 9 & $\begin{array}{l}\text { Avaliação de } \\
\text { irregularidades nos } \\
\text { serviços de alimentação } \\
\text { do município de Bagé e } \\
\text { elaboração de Cartilha de } \\
\text { Boas Práticas de } \\
\text { Manipulação. }\end{array}$ & BORBA, A. U. & 2014 & $\begin{array}{l}\text { Avaliação no periodo de } 2001 \text { a } 2014 \text { nos } \\
\text { serviços de alim entação autuados pela } \\
\text { Fiscalização Sanitária por falta de higiene. } \\
\text { Padarias e Confeitarias apresentaram o maior } \\
\text { percentual com } 54 \% \text { dos estabelecim entos } \\
\text { autuados, seguidos de } 16 \% \text { Superm ercados, } \\
12 \% \text { Restaurantes, } 7 \% \text { Açougues, } 5 \% \\
\text { Mercearias, } 4 \% \text { A } 2 \% \text { Lancherias } 0 \% \text { Bares. }\end{array}$ \\
\hline 10 & $\begin{array}{l}\text { LONGO afirm a que } \\
\text { superm ercados estão m ais } \\
\text { expostos às redes sociais }\end{array}$ & SOARES, F & 2018 & $\begin{array}{l}\text { A empresa ganhouum a responsabilidade maior } \\
\text { por suas ações, em função da rápida } \\
\text { repercussão criada na intemet. Não é uma } \\
\text { questão de estar na rede ou não, e sum das } \\
\text { consequências das ações da instituição. }\end{array}$ \\
\hline
\end{tabular}

Fonte: Autores (2019).

De acordo com os dados 2 e 6 da Tabela 1 e Tabela 2, ambos possuem resultados sobre avaliações realizadas no meio alimentício. Sendo no dado 2 feita em supermercados e feiras com diversos parasitos encontrados como: cistos de Entamoeba spp., Endolimax spp, Giardia spp, oocistos não esporulados, ovos de ancilostomídeos, larvas de nematódeos, ovos de Ascaris, ácaros e Trichuris spp.

Diferente do dado 6 que avaliou barra de mão de carrinhos e alças de cestas de supermercados, cujo o resultado encontrado foi a bactéria Staphylococcus aureus. Sendo as amostras do dado 2 coletadas diretamente de hortaliças (alface e agrião) e do dado 6 amostras advindas de barra de mãos de supermercado e alças de cestas.

Segundo Matos et al. (2012), em um estudo com amostras para identificação de fontes de contaminação de carne bovina em estabelecimentos alimentícios resultou com percentual de 100\% para Staphylococcus aureus. O que alega a presença da bactéria nas mãos dos manipuladores em quantidades insatisfatórias, indicando falha ou ausência do procedimento de lavagem das mãos.

Com relação às hortaliças, o estudo de Viera et al. (2010), no Rio Grande do Sul sobre parasitos, revela que os valores encontrados refletem condições e práticas de cultivo inadequadas do ponto de vista higiênico-sanitário. Dando assim a importância para a saúde pública, quanto enaltecimento no sistema da vigilância sanitária, de modo que haja maior fiscalização e consequentemente melhoria da qualidade higiênica, principalmente em feiras livres. 
O dado 1 também afirma que carrinhos de supermercado e mouses de cybercafé são objetos mais contaminados por bactérias entre utensílios usados no dia a dia, isso pode ocorrer devido a contaminações urbanas. Segundo Fernandes et al. (2012), o vínculo pode estar associado às barras de ônibus que disseminam bactérias, fungos e parasitos para seus usuários, podendo gerar linhagens bacterianas multirresistentes, o que aumenta o risco de infecções.

O dado 4 relata sobre o risco biológico advindo da precariedade da higienização em supermercados o que pode viabilizar a presença de animais transmissores de doenças como ratos e mosquitos ou de animais peçonhentos.

O dado 9 constata que os serviços de alimentação são autuados pela fiscalização sanitária por falta de higiene e nos rankings de estabelecimentos os Supermercados ficam em $2^{\circ}$ lugar.

De acordo com Pilla (2009), as razões mais frequentes de denúncias estão relacionadas à inadequada limpeza e/ou desinfecção e/ou problema estrutural, alterações nas características organolépticas e presença de pragas urbanas.

De acordo com Junior (2011), o lado positivo para o controle biológico é que além de reduzir a densidade populacional dos insetos e outras pragas, apresenta baixo impacto ambiental. Sendo esta específica para os organismos-alvo sem impactar significativamente os aplicadores e a qualidade dos alimentos produzidos.

Quanto aos dados 3 e 5, estes se referem a diferentes fatos que são de extrema importância para o ramo da alimentação. O dado 3 expõe que a falta de informação acomete a qualidade e credibilidade do estabelecimento. No dado 5 há relatos de inadequações de boas práticas que interferem nas condições higiênicas sanitárias.

De acordo com Bendini et al. (2012), o prazo de validade é umas das informações que o consumidor associa com a qualidade do alimento, pois interfere na questão financeira e na saúde.

Com relação às boas práticas, a seleção, a capacitação, a educação dos manipuladores e a avaliação das competências devem ser critérios seguidos à risca para o sucesso e alcance de um alimento seguro (Vidal-Martins, et al., 2014).

O dado 3 compadece do dado 7 que frisa o direito da informação e rotulagem, sendo que a principal intenção do Legislado é que se tenha produtos seguros, confiáveis e que não apresentem riscos à saúde de seus consumidores.

Levando isso em conta, o dado 8 afirma que os supermercados são os que estão com maior número de denúncias e, que pode ser devido ao contingente de pessoas ou pelos riscos de manipulação. O que correlaciona com o dado 10 referindo os supermercados mais susceptíveis à exposição na internet quanto a casos de más condutas.

Segundo Zini (2014), a televisão e a internet são os veículos de mídia que conseguem alcançar e atingir o maior número de pessoas ao mesmo tempo. A facilidade de acesso às propagandas televisivas, que possuem apelo audiovisual, faz com que a televisão ainda consiga ser superior a internet em termos de audiência, cobertura e frequência.

\section{Conclusão}

Em face ao objetivo proposto, pode-se concluir que discutir a importância da segurança do alimento e a proteção do consumidor na utilização dos carrinhos de supermercado apresentou contribuições para importância das boas práticas de fabricação; estabelecimentos atentos às legislações e a preocupação com contaminação de alimentos.

Com base nos estudos apresentados com comparação e assimilação de alguns, é possível concluir que existe uma relação entre as condições higiênico-sanitárias inadequadas com a qualidade microbiológica insatisfatória, resultando na contaminação. Seja advinda dos carrinhos de supermercado, mouses de cybercafé, feiras livres, animais em locais alimentícios, contaminação de objetos ou condição higiênica-sanitária de colaboradores. Para trabalhos futuros a fim de amenizar essa presença deve-se incentivar campanhas de higiene pessoal para indivíduos e ambiental evitando doenças e agravos.

Por outro lado, ainda se faz necessário um acompanhamento em longo prazo de treinamentos em estabelecimentos alimentícios, para melhor alcance da padronização e controle da qualidade. 


\section{Referências}

Assis, J. R., Assis, A. C. M, Nunes, D., Carlos, A. B., Carvalho, T. T. \&

Galdos, A. (2019). Micotoxinas no metabolismo e desempenho de animais ruminantes. Journal of Biology \& Pharmacy and Agricultural Management, 15, (4). ABNT. (2011). NBR 15287. Informação e documentação - Projeto de pesquisa -Apresentação. http://www.gepem.org/site/images/abnt15287com ofazerProjetodepesquisa.pdf

Bendini, N. I., Popolim, W. D. \& Oliveira, C. R. A. (2012). Avaliação do conhecimento e dificuldades de consumidores frequentadores de supermercado convencional em relação à rotulagem de alimentos e informação nutricional. Jornal Health Sci Inst., (3), 261-5.

Resolução RDC n ${ }^{\circ} 275$, de 21 de outubro de 2002. (2002). Dispõe sobre o Regulamento Técnico de Procedimentos Operacionais Padronizados aplicados aos Estabelecimentos Produtores/Industrializadores de Alimentos e a Lista de Verificação das Boas Práticas de Fabricação em Estabelecimentos Produtores/Industrializadores de Alimentos. Diário Oficial da União (Seção 1).

Resolução RDC n²16 de 15 de setembro de 2004. (2004) Regulamento técnico de boas práticas para serviços de alimentação. Diário Oficial da União. Brasília, DF.

Borba, A. U. (2014). Avaliação de irregularidades nos serviços de alimentação do município de Bagé e elaboração de cartilha de boas práticas de manipulação. Monografia do curso de Pós-graduação em Processos Agroindustriais - Universidade Federal do Pampa. Bagé.

Brasil. (2017). Decreto No 13.486 de 03 de outubro de 2017. Código de defesa do consumidor.

Fernandes, A. A. L.; Rangel, C. D., Sena, C. J. C., Rangel, C. V. \& Moraes, R. (2012). Diversidade de Bactérias, Fungos e Formas de Resistência de Parasitos em Duas Rotas de Ônibus do Transporte Coletivo da Grande Vitória, ES. Revista Sapientia, Vitória, (11), 39-45.

Gruetzmann, P. Q. (2015). Direito de informação do consumidor e rotulagem de alimentos. Trabalho de Conclusão do Curso de Graduação em Direito Universidade Regional do Noroeste do Estado do Rio Grande do Sul, Santa Rosa.

Estrela, C. (2018). Metodologia Científica: Ciência, Ensino, Pesquisa.

Freitas, V. C. (2018). Condições higiênico-sanitárias de açougues e supermercados de viçosa (mg). Revista Científica Univiçosa, 10 (1).

Junior, M. E (2011). Controle biológico de insetos pragas. I Seminário mosaico ambiental: olhares sobre o meio ambiente. Campos dos Goytacazes, Rio de janeiro.

Lima, A. L. I. (2018). Segurança de alimentos em uma rede de supermercados a partir da RDC 275: uma abordagem com auxílio multicritério à decisão. Acta Biomedica Brasiliensia, 9, (3).

Macedo. I. M. E. (2020). Avaliação bacteriológica da água de consumo em serviços de alimentação. Research, Society and Development, 9, (11).

Matos, V. S. R.; Gomes, A. P.P.; Santos, V. A.; Freitas, F.; Silva \& I. M. M. (2012). Perfil sanitário da carne bovina in natura comercializada em supermercados. Rev. Inst. Adolfo Lutz, 71, p.187-92.

Oliveira, D. B., Bombana, C. C., Rodrigues, G. A. G, Gonçalves, R; J. \& Parussolo. L. (2015) Caracterização de Staphylococcus aureus isolados da barra de mão de carrinhos e alças de cestas de supermercados. Rev. Ciênc. Farm. Básica Apl., 3, 407-412.

Pilla, C. S. (2009). Perfil das denúncias recebidas pelo programa de alimentos da vigilância sanitária de Viamão/RS. Monografia do curso de medicina veterinária - Universidade Federal do Rio Grande do Sul. Rio Grande do sul.

Pinho, J. P A. et al. (2020). Qualidade microbiológica de sanduíches tipo hambúrguer: uma revisão. Research, Society and Development, 9, (10).

Rios, T. C. (2012). Boas Práticas em supermercados e na central de armazenamento e Distribuição. Monografia do curso de engenharia de Alimentos Universidade Federal do Rio Grande do Sul.

Santos, N. M., Sales, E. M, Santos, A. B., Damasceno, K. A. \& Thé, T. S. (2009). Avaliação parasitológica de hortaliças comercializadas em supermercados e feiras livres no município de Salvador - BA. Rev. Ciências. Méd. Biol., 8 (2), 146-152.

Serretino, A. (2008). Novos canais e formatos no varejo de alimentos. Nota Técnica: Análise setorial do comércio varejista. DIEESE. (Nota técnica, $\mathrm{n}^{\circ}$ 74).

Silva, L. A. \& Correia, A. F. K. (2009). Manual de Boas Práticas de Fabricação para Indústria Fracionadora de Alimentos. Revista de Ciência \& Tecnologia, 16, (32), p. 39-57.

Soares, Fernando. (2018). Longo diz que supermercados estão mais expostos às redes sociais. Jornal do Comercio.

Sousa, A. A., Paz, A. N., Carvalho, L. M. F., Bezerra, K. C. Batista \&, Landim, L. A. S. R. (2020). Condições higiênico-sanitárias em unidades produtoras de refeições: uma revisão. Research, Society and Development, 9 (11).

Vidal-Martins, A. M. C, Bürger, K. P., Aguilar, C, E, G., Gonçalves, A. C. S., Grisólio, A. P. R., Rossi, G. A M. (2014). Implantação e avaliação do programa de boas práticas de manipulação em açougues do Município de São José do Rio Preto - SP. Revista Brasileira de Higiene e Sanidade Animal, 8 , p. 73 - 86,

Vieira, J. N., Pereira, C. P., Bastos, C. G G., Nagel, A. S., Antunes, L, \& Villela, M. M. (2010). Parasitos em hortaliças comercializadas no sul do Rio Grande do Sul, Brasil. Rev. Ciênc. Méd. Biol.,12, p.45-49.

Zini, A. L. (2014). A influência da propaganda no comportamento do consumidor de um supermercado em Clevelândia - PR. Trabalho de Conclusão de Curso em Administração - Universidade Tecnológica Federal do Paraná. Paraná. 